\title{
Arquitecto y arquitectura en los tratados españoles del siglo XVII
}

\author{
María Victoria García Morales
}

Quien en el siglo XVII ejerce la Arquitectura, se debate entre dos posiciones que, si no pueden calificarse de antagónicas, sí son la expresión de dos sentimientos distintos, producto ambos de unas circunstancias heredadas. Por una parte, la concepción artesanal de aquélla, que tiene su origen y procedencia en el medievo, en la que el artífice es consciente de su trabajo, basado en unos conocimientos adquiridos de sus antepasados y conforme a su condición. Por otra, una concepción científica de la arquitectura, basada en la nueva teoría artística propiciada por los humanistas italianos de siglos anteriores, que entiende la arquitectura como fruto de un proceso intelectual en el que tiene un papel primordial el hombre como ser capaz de entender, reflexionar y plasmar materialmente una idea.

En el siglo XVII conviven ambas experiencias, y aunque se pueda decir que la primera postura es la más generalizada, son numerosos los ejemplos que pueden presentarse de artífices que la ejercieron plenamente identificados con el nuevo pensamiento, haciendo de su oficio una profesión. Es esta última, la que puede considerarse precursora del arquitecto tal y como hoy en día se le entiende.

Nuestro análisis pretende dos objetivos, por una parte el estudio que, del concepto arquitecto y arquitectura, se tenía en este siglo, y un segundo propósito cifrado en los requerimientos que, merced a ese pensamiento, deberian reunir quienes se dedicaran a esta profesión.

Tiempo atrás surge un nuevo concepto de artista como consecuencia del pensamiento humanista, que en sus estudios y propuestas intervienen en el planteamiento y desarrollo de las Bellas Artes, porque éstas son manifestaciones del ingenio del hombre, porque revelan la primacia del 
intelecto, facultad que distingue al hombre de cualquier otro ser de la Naturaleza, porque destacan la individualidad, porque reflejan el poder, la cultura y el progreso de una sociedad. Estos eruditos reivindican su valor por la creatividad que suponen ${ }^{1}$, porque la concepción artistica permite ofrecer unos resultados que se admiran, no sólo por la calidad y riqueza de los materiales utilizados, ni por la pericia del ejecutor ${ }^{2}$, sino por ser una manifestación racional y sublime.

Esta proposición que intuye un modelo de artista nuevo respecto al marco establecido, en el que quienes se dedicaban a las Bellas Artes eran considerados como artesanos, debe argumentarse y comunicarse para connaturalizar a la sociedad y a los actores con los nuevos ideales.

Desde esta perspectiva el artífice medieval, despreciado en los círculos de poder en que se desdeñaba el valor del trabajo ${ }^{3}$, va a dar paso a una nueva figura: el artista educado y estudioso que desarrolla el conocimiento más que la habilidad y es aceptado en la sociedad, por la cultura, al mismo nivel que eruditos y poetas. La ocupación en las Bellas Artes no causará recelo en las familias con crédito social, es más, cuenta Condivi ${ }^{4}$ que Miguel Angel prefería como discípulos a jóvenes nobles que aprendices plebeyos, eco quizás de la resistencia que él hubo de vencer ante su familia al manifestar su vocación artística e iniciarse en el taller de Guirlandaio.

En este sentido dirigirán sus opiniones los escritores del Quattrocento protegidos por las refinadas cortes italianas ${ }^{5}$. Son los humanistas quienes formularán los principios artísticos y patrocinarán el cambio de ideas reclamando la liberalidad de las artes que creen gozaron en los tiempos clásicos, olvidados en la concepción manual del medievo, y asociando el prestigio social a una representación ciudadana teniendo como modelo la sociedad romana. Esto conduce a una fuerte demanda de obras artísticas, que proclaman el poder del comitente, a la vez que aumenta la economía y autoridad del artista, hechos que repercutirán en la estima de la sociedad, una vez mentalizada, hacia las Bellas Artes.

1 E. PANOOFSKY, Idea, Madrid 1978. Ofrece en su estudio el desarrollo histórico de este concepto.

2 M. Baxandall, Pintura y vida cotidiana en el Renacimiento, Barcelona 1978. Sin embargo, en los contratos que estudia se advierte gran celo en estas dos cláusulas.

3 L. Mumford, La ciudad en la Historia, Buenos Aires 1979, aunque este libro aborda otras cuestiones, señala esta constante.

${ }^{4}$ N. Pevsner, Las Academias de Arte, Madrid 1982, pág. 37. La educación artistica en paralelo al pensamiento humanista es el objeto de su trabajo.

5 J. BURCKHARDT, La cultura del Renacimiento en Italia, Barcelona 1979. 
Más que protagonistas, los artistas serán los beneficiarios de la nueva situación en que serán distinguidos por sus clientes ${ }^{6}$, circunstancias que ellos solos, sometidos a las leyes gremiales, no hubieran conseguido.

La organización gremial, en plena vigencia en el siglo $\mathrm{xV}$, que proporciona la enseñanza al principiante y regula su futuro trabajo, no ofrece, en absoluto, la formulación que ahora se pretende para el artista.

Si el mundo de las ideas actúa para provocar un cambio o para codificar unos anhelos latentes que debe orientar y dirigir, podemos decir que ambos fueron los motivos de la literatura artística producida en este momento.

Su intención primera es demostrar la conexión de la actividad artística con la de las enseñanzas liberales establecidas por la filosofía escolástica, como disciplinas que forman el espíritu, o, al menos, demostrar que el ejercicio de las artes plásticas no es un oficio sino la expresión del espiritu debidamente formado, que perfecciona la individualidad personal.

Los humanistas remodelan los Studia Generalia Medievales, dando paso a su filosofía que proclama el interés por el mundo, la naturaleza, el hombre, deposita su confianza en el ingenio y superioridad humana, en los métodos de la razón para adquirir el conocimiento que produce desarrollo o progreso.

Esta exposición tiene su correlativo en las artes para las que se revela una nueva dirección que revoluciona, tanto teórica como prácticamente, el marco establecido, en que éstas, utilizadas como expresión de las ideas religiosas no miran a la naturaleza o realidad circundante sino que se manifiestan por medio de símbolos que enseñan los dogmas y se desarrollan en la colectividad del gremio, que impide la individualidad y establece las competencias exclusivas de pintores, escultores y arquitectos.

Se establece que la actividad artística implica un discurso mental semejante al realizado en las disciplinas liberales, pues no es una producción mecánica sino que:

6 Son múltiples los ejemplos que se pueden señalar. Ver al respecto J. Gállego, El pintor de artesano a artista, Granada 1976. 
«...compromete una disposición total del alma que planea por encima de las contingencias..." ",

equiparable su acción a la de la Retórica, con la que intuitivamente se pone en paralelo ${ }^{8}$. Es Alberti quien muestra la analogía de ambas al considerar en el proceso creativo sus mismas tres fases: idea, distribución de las partes y revestimiento sensible. Para lo cual es necesario el ingenio o intervención del espíritu que selecciona la materia y el estudio de los modelos por medio de métodos científicos: el Dibujo y las Matemáticas, disciplinas que dominan a toda materia y conducen a la unidad de las Artes en su gestación, cuyo producto es el artista individual, que por su preparación es hábil en cualquier manifestación. Leonardo decía a sus discípulos:

«...estudia primero la ciencia que de ella nace la práctica...»"9

Esta es la tarea de los primeros escritores, difundir el nuevo pensamiento, la teoría que provoca y fundamenta las actitudes, y recoger los adelantos de Bruneleschi, Masaccio y Donatello, exponentes de una generación de artistas que inician los nuevos modos de concebir y expresar el arte.

Por ello los autores de la nueva doctrina artística tanto son los eruditos humanistas como los propios interesados y a quienes compete su proclamación y codificación.

Sin embargo, vemos que las ideas más claras son las que ofrecen quienes conjugan el ejercicio de su arte con una serie de relaciones externas que despiertan su inquietud, hombres que no proceden de una formación tradicional en el taller (Alberti, Leonardo) o que pretenden liberarse de él (Brunelleschi, Miguel Angel) ${ }^{10}$.

Señalado el objetivo de las artes visuales en recrear y formar el espíritu, como subrayaba Boccaccio elogiando a Giotto por haber sacado a la luz un arte enterrado por el error de los que

A. Chastel, Arte y Humanismo en Florencia en la época de Lorenzo el Magnífico, Madrid 1986, pág. 121.

* R. W. LEe, Ut pictura poesis. La teoría humanística de la pintura, Madrid 1982. Referido a la relación tradicional pintura-poesía.

9 N. Pevsner, obra citada, pág. 38.

10 Brunelleschi, consciente de su valía no pagará las cuotas gremiales por lo que llega a ser encarcelado. 
"...más bien pintaban para agradar a los ojos del ignorante que para complacer a la inteligencia del sabio..." ",

los escritos artísticos ofrecen los modelos que derivan del nuevo sistema - las formas góticas no son válidas para expresar el dominio del hombre sobre la naturaleza - asumiendo el repertorio de la Antigüedad: los edificios y esculturas romanos que muestran la grandeza del hombre, el esplendor de la civilización ${ }^{12}$.

Surge, así, una primera literatura artística acorde con una fase inicial de divulgación de las nuevas ideas ${ }^{13}$.

Exponen los principios intelectuales en que se fundamenta su ejercicio al formular su doctrina como resultado de su estudio y experiencia, $y$, aunque no presentan los cauces oportunos de enseñanza, la concreción de sus programas en una escuela que sustituyera al aprendizaje gremial, contribuyen a connaturalizar a los talleres y a la sociedad con los nuevos planteamientos y repertorios formales.

Realidad o necesidad educativa que tampoco asumen las Academias creadas desde el siglo xv. Las Academias, y desde el punto de vista que nos interesa las de Arte, son el motor, el fermento de las nuevas ideas, son la suprema autoridad doctrinal, representación de los grandes espíritus, pero ya planteadas como reuniones informales o como empresas reglamentadas a las que acuden los «belli ingegni especialmente los de la aristocracia" no protagonizan la reforma docente. En este sentido manifiesta su parecer Pevsner en su estudio sobre las Academias de Arte, al comparar dos grabados que representan a varios artistas, cada cual a su trabajo en el taller del escultor Bandinelli, deduce que aun en los talleres más avanzados estas reuniones no eran docentes, sino que su objetivo era:

«...disfrutar dibujando en compañia bajo la mutua supervisión y discutiendo sobre la teoría y la práctica del arte..." ${ }^{14}$,

y a propósito de la "Academia del Disegno", fundada por Vasari:

1 A. Chastel, obra citada, pág. 110.

12 V. Nieto Alcaide, F. Checa Cremades, El Renacimiento. Formación y crisis del modelo clásico, Madrid 1980. Roma ofrece el modelo que el Renacimiento recreará.

13 J. Ramirez, Construcciones ilusorias. Arquitecturas descritas. Arquitecturas pintadas, Madrid 1983.

14 N. Pevsner, obra citada, pág. 42. 
“...no se estaba considerando una sustitución de la preparación de taller por algo que podía llamarse preparación académica..." ${ }^{15}$

De este modo, la renovación de las artes iniciada por los espiritus avezados desde el plano teórico que suponen las Academias o la literatura artística y desde el campo de las realizaciones con ejemplos que asumen nuevos repertorios formales y técnicos, conlleva unos factores positivos que podríamos enumerar en calificativo de arte para una actividad que hasta ahora era trabajo, atención de la sociedad o por el momento de los círculos influyentes, los posibles clientes, al producto artístico por cuanto le reporta prestigio, diferente estima a quienes ejercen ese arte, a los cuales se dispensa un trato "principesco" o simple ascenso de categoría social por el beneficio económico que reporta la protección y la demanda. Mas plantea una exigencias formativas y de organización del trabajo que no resuelven inmediatamente por lo que durante casi dos siglos es constante la insistencia en la defensa, por teóricos y artistas, de estos principios conseguidos, así como la búsqueda de un marco educativo y laboral que responda a las nuevas propuestas.

\section{LOS TRATADOS DE ARQUITECTURA}

Iniciado el camino, el objetivo de los nuevos escritos y artistas, conscientes de la dicotomía de la creación artística, es formular su doctrina, obviando inmiscuirse, excepción de los Prólogos, en la teoría general de las Artes, subrayando las disciplinas y técnicas específicas que permiten dominar la materia, convertir su arte en ciencia y no en utopia.

Se inician con un preámbulo grandilocuente en el que se ensalza la excelencia y dignidad de la Arquitectura remontando sus orígenes al mítico Dédalo y a Dios, supremo arquitecto. Narran la atención que le han prestado los grandes príncipes y favores que concedieron a quienes fueron sus arquitectos. Enumeran las disciplinas necesarias al futuro profesional para conseguir la perfección en la obra. En el afán de enaltecer su figura, de asociar su imagen a la de los humanistas eruditos, el abanico propuesto es sumamente amplio, como dice Pitias «...capacitado en todas las artes y las ciencias..." la visión lúcida de Alberti le hace pro-

15 Ibidem, pág. 46. 
poner únicamente los conocimientos necesarios a su quehacer: Dibujo y Matemáticas.

Italia y sus edificios antiguos son la fuente de inspiración de los tratadistas, en ellos se encuentra el buen construir, desentrañar el misterio de su apariencia mediante la observación, medición y relación de sus partes es el objetivo para conseguir un sistema constructivo nuevo, no mera copia de los ejemplos. Hablan de la proporción y propiedades de los órdenes, de los ornamentos, los lugares favorables, el material adecuado.

El método propuesto por los arquitectos italianos es, pues, el estudio científico de las ruinas romanas para reinterpretar la Antigüedad desde el punto de vista de la práctica moderna. Siempre apoyados en la autoridad de sus antecesores y en su propia experiencia, por lo que pueden correr el riesgo de derivar a consejos prácticos, a proporcionar recetas útiles para resolver los problemas, apartándose del razonamiento teórico que exigen al arquitecto al inicio de sus Tratados. Muchos de estos escritos adquieren por ello valor de manuales, de instrucciones que permiten, sin mucho esfuerzo, realizar obras que se ajustan a los moldes establecidos y aseguran la continuidad de las formas. Sólo en algunos encontraremos crítica y desarrollo de nuevos planteamientos compositivos.

Como a la transformación del marco teórico no le acompaña la renovación del sistema de enseñanza, ni de la organización del trabajo, convivirán durante mucho tiempo dos figuras diferentes e incluso opuestas: el maestro de obras, que ejerce la arquitectura según lo aprendido en el taller, y el arquitecto científico, posteriormente técnico, que se define en los Tratados. Para estos últimos los primeros sólo serán los instrumentos de los nuevos profesionales, como dice Alberti:

“...Antes de ir más lejos, creo que será conveniente decir a quién se puede llamar arquitecto con justicia; no os propondré, desde luego, a un oficial de carpintería pidiéndoos que lo consideréis igual al hombre profundamente instruido en otras ciencias, aunque el hombre que trabaja con sus manos sea el instrumento del arquitecto..." ${ }^{16}$.

Aunque es claro que arquitecto desde el siglo XVI, por influencia italiana, significa una profesión diferente a la de maestro de obras y que

${ }_{16}$ L. B. Alberti, Los Diez Libros de Arquitectura, Edición facsímil de la de Madrid, Alonso Gómez, 1582. Valencia 1977. Libro I, Proemio del autor, pág. 1. 
tendría que ser utilizado sólo para designar a quienes cuentan con una preparación según los principios humanistas, advertimos que el maestro de obras examinado, al estar protegido por la organización gremial, debilitada pero en vigencia hasta el siglo XVIII, se cree en el derecho de utilizar la nueva denominación y autotitularse arquitecto, bien por el prestigio que el término conlleva, bien porque efectivamente su formación responde a la propuesta. Por lo que hasta que se establezca un sistema que ampare y forme al nuevo profesional, su realidad será una afirmación personal, cierta, exclusivamente, en figuras relevantes que conocieron y asumieron las nuevas ideas. Esto nos permite emplear indistintamente arquitecto o maestro de obras al referirnos a quienes asuman las funciones que la Arquitectura requiere: diseñar, dirigir, realizar, etc.

La difusión de estas ideas, nacidas en el siglo Xv a partir de la formulación, sin fecha concreta ni manifiesto, de los principios humanistas, es relativamente acelerada en Italia, donde sus respectivos Estados presentan unas coordenadas políticas y sociales favorables, pero es en el siglo XVI cuando el proyecto italiano se exporta a Europa, con la misma carencia inicial, es decir, sin ofrecer un método de aprendizaje y el modelo de organización laboral.

\section{SU CONSECUENCIA EN EL SIGLO XVII ESPAÑOL}

El panorama artístico del final del siglo XVI está marcado por la influencia de Juan de Herrera, a quien Felipe II nombra su arquitecto utilizando el término sin ambigüedad ${ }^{17}$. Influencia que se prolongará hasta muy avanzado el siglo XVII, según las zonas, dependiendo de la proximidad a los centros cortesanos y de decisión. Pero si Herrera tuvo incidencia en el significado también la tuvo en el significante, según la doctrina de Vitrubio, extremos que conciernen a quien ejerce la Arquitectura. La educación de Herrera en nada le aproximan a la tradicional formación de taller establecida para los maestros de obras ${ }^{18}$, poco conocemos de su

17 El término "arquitecto" será empleado sin escrúpulo por muchos. A Herrera se le nombra arquitecto en el sentido enunciado por Alberti.

${ }_{18}$ La figura de Juan de Herrera ha sido objeto de muchos estudios monográficos, entre ellos señalamos el de A. RUIz ARCAUTE, Juan de Herrera Arquitecto de Felipe II, Madrid 1936. 
preocupación por mejorarla o cambiarla pues su precedente no se encuentra en él. Herrera representa una profesión nueva, iniciada en Italia, y ejercida bajo la protección de un Rey humanista ${ }^{19}$. Su figura es el paradigma, marca el modelo de lo que debía ser un arquitecto; humanista, científico, cortesano. A esta tarea sí dirige sus esfuerzos como director de la Academia de Matemáticas, favoreciendo la traducción de libros de esta materia, que sobrevuela todo quehacer científico, arquitectura, cosmografía, ingeniería ${ }^{20}$.

Naturalmente, la personalidad de Herrera va a hacer escuela, primeramente, en sus discipulos y seguidores, entre los que se puede contar a Francisco de Mora, sucesor de Herrera en el puesto de Arquitecto Real, Juan Gómez de Mora, Juan Bautista Monegro, Juan de Nates, Diego de Praves y su hijo Francisco, etc. Sin querer afirmar que estos hombres fueron, durante el siglo XVII, los portadores de las nuevas ideas, señalamos que es con ellos con los que éstas se prolongan, por otros maestros de todas las épocas del siglo, y entre los que señalaremos a Fray Lorenzo de San Nicolás, Juan de Torija, Domingo de Andrade, Teodoro Ardemans, etc.

Al analizar la situación artística del siglo precedente, no cabe duda que la teoría artística italiana ha llegado a la península. Sus tratados principales han sido traducidos, no por otros que por arquitectos, bajo la protección real o los nobles. Se han publicado libros que hablan de las novedades producidas ${ }^{21}$, se construye según los modelos italianos, con un desfase cronológico mínimo, reinterpretando lo recibido como nota diferenciadora ${ }^{22}$, hechos que revelan una situación favorable a la Arqui-

19 J. Rivera Blanco, "La elección del Arquitecto una cuestión de estilo", Ideas y Diseño (La Arquitectura), IV Centenario del Monasterio de San Lorenzo de El Escorial. Madrid 1986, pág. 47-64.

20 Sobre esta Academia Llaguno ofreció las primeras noticias ampliadas por diversos autores, entre otros: J. REY PASTOR, Los Matemáticos españoles del siglo xVI, Madrid 1893, pág. 129; A. Rulz ArCaute, obra citada, pág. 97; J. Simón Diaz, Historia del Colegio Imperial de Madrid, Tomo I, Madrid 1952, pág. 47; V. TOVAR MARTín, La arquitectura madrileña del siglo XV\| (Datos para su estudio), Madrid 1983, pág. 93; A. Camara Muñoz, Elementos manieristas de la Arquitectura del primer barroco español: Arquitectura y Sociedad en el reinado de Felipe III, Madrid 1987, pág. 170.

21 Traducen a Vitrubio los arquitectos Lázaro de Velasco y Miguel de Urrea; a Alberti, Francisco Lozano; a Serlio, el arquitecto jesuita Villalpando; a Vignola, el pintor Patricio Cajés. Se ha publicado el "Libro de Arquitectura" de Hernán Ruiz (el Joven), "el Libro de trazas de cortes de piedras" de Alonso de Vandelvira, "Discurso de la Figura Cúbica" de Juan de Herrera, "De varia conmensuración para la Escultura y la Arquitectura", de Juan de Arfe y Villafañe. Sobre este tema la bibliografía es abundante, tanto en Repertorios como en publicaciones de ediciones facsímiles.

${ }_{22}$ M. Gomez Moreno, Las Águilas del Renacimiento, Madrid, en su estudio observa 
tectura, principalmente debido al entusiasmo del rey Felipe $\|^{23}$. Es cierto, también, que ofrecemos una muestra, quizás no válida porque estas circunstancias se dieron sólo en unos pocos, próximos a los círculos cortesanos, pero a pesar de ello el nuevo concepto de profesional así como las realizaciones o intervenciones al estilo "antiguo", se imponen poco a poco.

Se produce la misma situación que en el país vecino un siglo antes: el desfase de una élite formada, que asume integramente el planteamiento y una sociedad no preparada para las novedades, que se dejará o no conducir, por lo que el camino es lento para el amanecer de la profesión.

La tratadística antigua y próxima continúa su difusión durante el siglo XVII, en las bibliotecas de muchos maestros aparecen las obras de los más conocidos: Vitrubio, Alberti, Serlio, Vignola, Palladio, Delorme, Labacco, traducidos o en su lengua original, autores que ejercen gran influencia en el pensamiento arquitectónico del momento bajo varios aspectos: por sus divagaciones prologales, en las que ensalzan la Antigüedad, superioridad y estima concedida en todos los tiempos a la Arquitectura, condicionando su esplendor a la protección de los príncipes e insistiendo en los favores otorgados a sus arquitectos; por sus exposiciones doctrinales en que contemplan los principios de la Arquitectura, por sus desarrollos prácticos de los problemas formales. De este repertorio cada maestro escogerá aquello con lo que más se identifique, y encontraremos a unos que aprenden los Prólogos por la repercusión social que entraña, éstos serán los que harán clamar a clientes y profesionales por la confusión y fraudes a que dan lugar; otros aprehenderán el concepto de Arquitectura así como la formación que conlleva, por esta vía se irá perfilando el camino; otros, en fin, que simplemente los utilizaron como modelos o libros de pautas, apartándose definitivamente de la nueva profesión.

En general, puede decirse que es un siglo de reivindicación desde dos polos opuestos: el taller y el profesional, pues en ambos extremos se advierte y defiende que la Arquitectura no es oficio, sino un Arte o más bien una Ciencia - pues comporta ella misma sus propias normas y

cómo es grande la influencia de Siloé y Berruguete porque aunan las novedades y la tradición.

${ }^{23}$ J. Rivera Blanco, Juan Bautista de Toledo y Felipe II. La implantación del Clasicismo en España, Valladolid 1984, pág. 56-64. 
el criterio de su existencia- y que es necesaria una formación sólida, no sólo en el ejercicio, sino en la teoría, es decir, adquirir la doctrina.

Sin embargo, la situación económica y social del siglo XVII no facilita la fructificación de esta semilla pues en general, no se emprenderán grandes obras, origen y fermento de toda novedad, y la organización gremial, en plena vigencia, tampoco favorecerá un tipo de maestro concebido liberalmente, sin sujeciones y, lo que es más importante, donde su formación transcurra por otros cauces que no tengan nada que ver con la adquirida en el taller, fundamentalmente práctica, sino basada en el estudio de unas disciplinas que le permitirán crear, elucubrar, entender el hecho arquitectónico como un todo y no resumido a la práctica de su realización.

En una sociedad marcada por la depresión económica y las guerras, es normal que la intención de sus miembros sea la de sobrevivir, lograr los medios económicos necesarios para ello, y en el plano de los arquitectos lo general puede considerarse apartar las inquietudes intelectuales y lograr hacerse con las obras que surgieran, es decir, priman los intereses económicos sobre los intelectuales, por lo que el maestro tradicional, protegido por una organización, seguirá ocupándose del quehacer arquitectónico. Aparecen escritos que denuncian la relajación del sistema de aprendizaje y la facilidad de conseguir la titulación de Maestro y reclaman una formación mejor para evitar la deshonra, no sólo de un nombre, sino de la Arquitectura. Como denuncia Torija en su Tratado breve sobre las Ordenanzas de la Villa de Madrid:

"...Todos estos daños se evitarían si la Coronada Villa de Madrid, por Ordenanza, mandara, hubiera aprobación con riguroso examen de Maestros; y Alarifes, para serlo, hácese posible este daño, porque de la noche a la mañana algunos se acreditan de Maestros, que en serlo, es destruir, y no aprovechar a la República, y los Maestros científicos no son conocidos, a causa de tanto zángano..." ${ }^{24}$.

Si bien la terminología empleada para designar a los profesionales de la arquitectura, estaba marcada por el máximo grado alcanzado dentro

24 J. ToRIJA, Tratado breve sobre las Ordenanzas de la villa de Madrid y policía de ella, Madrid 1760. Antonio Pérez Soto. Colección Magerit, dirigida por Luis Cervera Vera, Madrid 1979, pág. 18. 
de la organización gremial, Maestro, está claro que los interesados trataran de distinguirse, no por denominarse arquitecto, sino mediante la ostentación de unos conocimientos adquiridos con su propio estudio, que nunca omiten citar en los memoriales presentados con la pretensión de ocupar una plaza ${ }^{25}$, a fin de diferenciarse de otros maestros manuales, prácticos, que presumiblemente no los poseyeran. Aqui hemos de decir que si bien todos los maestros se sentían capaces de levantar una obra, un edificio, con mayor o menor fortuna, la función o el papel que desarrollaron frente al hecho constructivo y arquitectónico es el que realmente va a diferenciarles. No cabe duda, a la vista de muchos de los escritos a los que nos referimos, que el nuevo profesional está aún por definir.

Este profesional ha de ser compatible con una organización gremial, útil en el sistema de trabajo, que no interesa o no se puede suprimir ni modificar. Surge de entre ellos, por un esfuerzo personal de asimilación de las nuevas teorías, como fruto de las exigencias de una clientela que lo demanda. Existirá entonces, especialmente, en los círculos próximos al poder y la influencia, donde se da mayor importancia al planteamiento que a la realización, que es una consecuencia lógica de un proyecto y dirección adecuadas.

La nueva concepción del profesional cala lentamente en el ánimo de los maestros del siglo XVI; podría incluso decirse que de forma inconsciente, y muy seguramente por motivos diferentes a los meramente intelectuales. Sabe que los puestos que les darán prestigio sólo los alcanzará si es capaz de competir y superar, por su preparación, a otros maestros, por lo que se obligará a realizar ese esfuerzo personal en el estudio. Por otra parte, se pretende, en términos generales, que los maestros, desde el taller, adquieran los conocimientos teóricos necesarios, aun simplemente para realizar, para mejorar de forma cualitativa la profesión, y así lo manifiestan en sus escritos.

A través de los escritos del siglo XVII es posible hacerse una idea de la realidad del mismo y a todo lo largo de él, puesto que al ser de diferentes fechas son una muestra de su sentir: hablan Praves y Juan Gómez de Mora, entre otros, a principio de siglo, Villalpando, López de Arenas, Fray Lorenzo de San Nicolás, Juan de Torija, Fray Juan Ricci, Juan Caramuel a lo largo de él, y terminando la centuria Domingo de Andrade y, posteriormente, Teodoro de Ardemans.

25 Las obras de patrocinio real, municipal o eclesiástico, ofrecían a los maestros puestos de trabajo fijos, que representaban un gran prestigio. Para cubrir las vacantes que se producían, los interesados enviaban memoriales con su formación y cualidades. 
Unos se extienden en enseñanzas de tipo teórico o técnico con diveras consideraciones sobre la Arquitectura; entre estos debe incluirse el de Caramuel, aparecido en 1678, y el Tratado de Bóvedas de Torija. Otros pretenden resumir o hacer una compilación de consejos prácticos para los que van a desarrollar alguna labor responsable, como la de Alarife, dentro de la Arquitectura, en este tipo hay que inscribir el de Torija, sobre las Ordenanzas para la Villa de Madrid.

Una idea se revela como constante en todos ellos y es que se ha asumido que la Arquitectura es Arte y Ciencia. En este doble sentido se pronuncia Francisco de Praves, en su traducción de los libros I y III de Palladio:

"...la necesidad de saber el Arte de la Arquitectura me ha obligado (para mejor entenderla) a estudiar la lengua toscana, y traducir algunos autores, que están escritos en ella, en la nuestra castellana, para que con menos trabajo, y más facilidad, se entiendan los preceptos de esta ciencia.... ${ }^{26}$,

opinión que comparte Torija, al escribir en su Tratado de Bóvedas:

“...Pretendiente la Antigüedad, de que los hombres trabajasen, por alcanzar las ciencias fugitivas, hizo pintar las Artes en formas diferentes de hermosísimas mujeres, a las cuales los hombres, como galanes naturales, solicitasen el empleo fecundo de la hermosa ciencia, a quien su genio se inclinase por medio del afán de mi estudio práctico y especulativo, he llegado a enlazarme con la Arquitectura, dama hermosa cientifica, a quien he galanteado desde mis verdes años...” ${ }^{27}$.

a la que según J. Caramuel:

“...acompañan a la Arquitectura muchas facultades y Ciencias, pero de diversa manera: porque las unas le son necesarias a un Ingeniero o Maestro de Obras: y las otras le ennoblecen y adornan..." ${ }^{28}$.

26 F. Praves, Traducción de los libros $/$ y $/ / 1$ de $A$. Palladio. Edición facsímil de la de Valiadolid, 1625. Valladolid 1986. Prólogo al lector.

${ }_{27}$ J. ToRIJA, Breve Tratado de Bóvedas. Edición facsimil de la de Madrid, 1661, por Pablo de Val, impresor. León 1983. Prólogo al lector.

28 J. Caramuel, Arquitectura Civil Recta y Oblicua. Edición facsímil de la Camilo Corrado. Imprenta Obispal. Año 1678. Madrid 1984, Tomo I, pág. 11. 
La cualidad de Ciencia y Arte para la Arquitectura merece, por parte de Domingo de Andrade un capítulo de su Tratado Excelencias, Antigüedad y Nobleza de la Arquitectura ${ }^{29}$. Constante común en todos los tratados del siglo es el concepto de Ciencia para la Arquitectura, alejada tanto de la realización manual como del concepto exclusivamente artístico, aunque no dudan en proseguir narrando en los Prólogos su implicación con las Artes del Dibujo, para seguir reclamando su liberalidad. Se pasa del concepto de arquitecto artista al de arquitecto científico, entendiendo como tal al que ejerce la Arquitectura.

La primacía de la idea sobre la realización, del proyecto sobre la ejecución, requiere que el arquitecto adquiera la doctrina, es decir, el conjunto de su saber específico que se compone tanto de una teoría con la que domina los principios de solidez, utilidad y belleza, que rigen todo edificio, como de una práctica que le permite saber lo que es realizable, cómo y a qué precio.

Para Andrade al arquitecto le pertenece:

"...dar forma, traza, y disposición en las obras, como en los palacios, y casas tócale disponer salas, dormitorios, puertas, ventanas, y las más piezas convenientes, y escoger y elegir los materiales..." ${ }^{30}$.

Se perfila, de esta manera, al arquitecto como profesional que emplea su conocimiento para expresar la Idea con las instrucciones precisas para que se pueda realizar sin su intervención. Por ello cobra nuevo realce la figura del Trazador o tracista, identificado para Gómez de Mora con el arquitecto de nuevo cuño, quizás comprendiendo la ambigüedad del término arquitecto. En este sentido, sus palabras son esclarecedoras ya que valora al Trazador en cuanto que es quien ejercita los preceptos de la Arquitectura, que como bien dice, está delimitada por la práctica y la teoria, fábrica y raciocinio:

“...Entre las calidades que se requieren en el perfecto Trazador, no es la menor, el haber de ser ingenioso, "para poder con más destreza ejercitar los preceptos de la Arquitectura. La cual tiene su origen, y se

29 D. AndRade, Excelencias, Antigüedad y Nobleza de la Arquitectura, en la obra de F. Sánchez Cantón Opúsculos gallegos sobre arte de los siglos XVII y XVIII, Santiago de Compostela 1956.

30 D. ANDRADE, obra citada, capítulo "Antigüedad de esta Ciencia", pág. C5. 
compone, ex fabrica et ratiocinatione. Aquella no es otra cosa, que una continuada y trillada meditación del uso"» ${ }^{31}$.

cita que toma de Vitrubio y que no implica ninguna manualidad o mecánica en la obra sino las funciones de dirección y técnica. En este punto coincide Andrade, prácticamente ochenta años más tarde cuando afirma:

«...porque el Arquitecto (como dice Platón) es el que gobierna a los que usan de las artes, donde no es artífice, ni oficial, sino un director de artificios y de artífices...." ${ }^{32}$.

Juan Gómez de Mora reconoce que es en la realización de las trazas donde se muestra toda la ciencia y conocimientos del arquitecto y que requieren un estudio muy cuidadoso de la obra:

«...reconociendo la Junta, a cuya disposición y cargo está esta obra, el continuo estudio que fábrica tan suntuosa requería y que con su aplicación y fuerza de inventiva se le irian ofreciendo al arquitecto nuevas dificultades, para conseguir su mayor perfección tuvo por bien que se pusiera esta condición..." ${ }^{33}$.

Condición que hace referencia a que los maestros que realizaran la obra seguirian las trazas de Juan Gómez de Mora, así en las plantas como en los perfiles que se les irían dando según fuera avanzando la obra. Juan Gómez de Mora, conocedor de esta cláusula, afirma:

«...de que se colige le dieron facultad para ir ajustando la obra a reglas de perfecta Arquitectura..." ${ }^{34}$

El pensar de Juan Gómez de Mora es claro: la excelencia arquitectónica de una obra radica en la traza de la misma, función que sólo será capaz de asumir el arquitecto con los conocimientos y formación propuestas. Torija insiste en la misma dirección al afirmar:

31 J. GOMEZ DE MORA, en su escrito de defensa «a la acusación y cargos que se le han puesto acerca de las obras del Palacio y Alcázar Real de la Villa de Madrid", expone sus ideas sobre la Arquitectura y la profesión. (Documento publicado por $\mathrm{V}$. Tovar Martín, obra citada, Madrid 1983, pág. 470-485). Punto segundo, párrafo séptimo.

32 D. ANDRADE, obra citada, "Prueba de que la Arquitectura Militar y la Civil sea una misma", pág. E4.

33 Ver cita 31 , punto cuarto, párrafo 13.

34 Ibidem. 
"...Hijos son, y parto del entendimiento, y de las ciencias, los dibujos, y modelos, a cuya ejecución se han de reducir los edificios..." ${ }^{35}$.

Juan Gómez de Mora, defiende su profesión desde un punto de vista moderno, no entra en la realización práctica de la obra que corresponde, a su juicio, a los Maestros de obras, título que él también posee. Siendo uno el oficio, marca unas diferencias claras entre los dos aspectos, Trazador y realizador, él se considera entre los primeros y, lógicamente, en un plano intelectual superior al de los maestros realizadores.

En sus escritos no oculta que sigue puntualmente el pensamiento de Vitrubio y sus cualidades para ser un perfecto Arquitecto, y en su apología sitúa al Trazador en un nivel creativo y de elucubración arquitectónica a nada sujeto, al que no se le pone más límite superior que el cliente, como dueño de lo que se va hacer:

«...El favor que los señores Reyes antiguos hicieron en tiempos pasados al oficio de Arquitecto o Trazador, como tan importante a la República y los señores Reyes de España han observado lo propio, dando entrada, y ahora en su Cámara, a los que han tenido el oficio de Trazador y encargándose de las trazas... de donde proviene, no haber en la Casa Real ministro, ni criado, que no tenga entendido, que el oficio de Trazador no ha tenido otro superior para ver de dar cuenta de lo que se va trazando que a su Majestad..." ${ }^{36}$.

Interpretamos que ante la obra, la necesidad constructiva, se da una comunicación entre la idea y el cliente que no existirá entre éste y el realizador, puesto que éste no tiene que seguir más que lo que está trazado y aprobado por aquél.

Estos postulados figuran en todos los escritos de la época, no sólo en los autores cuya intención es contribuir a la excelencia de la Arquitectura, sino también en aquellos dirigidos a la formación de los futuros profesionales, aun en los más prácticos e incluso en los de denuncia. Formación que se reclama por todos los lados, que no proporciona en su totalidad el taller de la obra y que deben de lograr por su propio esfuerzo quienes tienen ilusión y estima por su quehacer. Francisco de Praves, hijo de Diego de Praves, en su traducción de los libros de Palladio, hace referencia a los estudios que, para lograr un perfecto dominio

36 Ver cita 31, punto cuarto, párrafo 14. 
de la Arquitectura, se ha visto obligado a realizar desde sus tiempos de aprendiz, llegando al conocimiento de otras lenguas.

Otro de los tratadistas de mayor consideración del siglo XVII es Fray Lorenzo de San Nicolás, cuya obra Arte y Uso de la Arquitectura va dirigida a los futuros Maestros. En él intenta informarles de los principios de la Arquitectura y exponerles de una forma didáctica sus reglas y técnicas, fin que podemos deducir que consigue estimulado por sus propias carencias ${ }^{37}$. Aunque su contenido teórico sea débil sus páginas son una denuncia válida de la situación; hay que tener en cuenta que Fray Lorenzo vivió gran parte del siglo XVII.

Los mismos requerimientos y las mismas exposiciones se encuentran en los dos libros de Torija Tratado de las Ordenanzas de Madrid y Breve Tratado sobre todo género de Bóvedas.

A finales de siglo, 1695, se publica el Tratado de Domingo de Andrade Excelencias de la Arquitectura, que es prácticamente contemporáneo con las Ordenanzas de Teodoro de Ardemans. Andrade, como se sabe ${ }^{38}$ es un arquitecto de formación humanística universitaria, erudito. En su Tratado va dando argumentos por los que atribuye a la Arquitectura la nobleza y antigüedad que reivindica. La parte quizás más interesante es la que dedica a la Arquitectura Militar y Civil. Es un hecho la tendencia a etiquetar la arquitectura, "arquitecto militar", "arquitecto de puentes», "arquitecto civil», etc., como si cada una de ellas supusiera una parcela independiente de la Arquitectura, lo que sin duda tiene su origen preciso en la formación recibida, casi personal, mediante el maestro, al que no podía pedírsele un conocimiento universal y estaba obligado a enseñar lo que él sabía. Andrade razona la unidad de la Arquitectura, sin etiquetas ni parcelas, todo es Arquitectura:

"...Y asi digo, que este nombre de Arquitectura es genérico, y que se amplia por sus individuos, y no se divide.... ${ }^{39}$.

En efecto son los que ejercen la arquitectura, en todas sus especialidades, los que contribuyen a engrandecerla y su conocimiento abarca

${ }^{37}$ Fray Lorenzo en su Tratado dedica unas páginas a hablar de su vida y cómo los primeros contactos con la profesión son junto a su padre, maestro de obras, y cómo sus inquietudes personales le llevan al estudio de los Tratadistas.

38 A. Bonet Correa, La Arquitectura en Galicia durante el siglo xvil, Madrid 1966, pág. 359 .

39 D. ANDRADE, obra citada, pág. E4. 
todas sus posibles aplicaciones. Los argumentos de Andrade se basan en la similitud o igualdad de los conocimientos necesarios para ejercerlas, sus elementos, lo único que cambia es la nomenclatura:

"...lo que se usa en la Civil, se usa en la Militar..." ${ }^{40}$.

Aunque las Ordenanzas de Madrid, de Teodoro de Ardemans, se publicaron en 1719, hay que considerar a su autor también arquitecto del XVII, pues fue durante esta centuria cuando alcanzó la mayoría de los cargos de relevancia y en 1700 la Maestria Mayor de Obras Reales.

Insiste, como Andrade, en resaltar el origen, mérito y dignidad de la Arquitectura ${ }^{41}$, y está principalmente interesado, a pesar del carácter práctico de su libro, en resaltar el fundamento intelectual que la rige, por lo que son múltiples los conocimientos que propone para el futuro profesional.

No cabe duda, incluso iniciado el siglo XVIII, se continúa, con los mismos argumentos y ejemplos, el debate iniciado siglos anteriores para defender la nobleza de la Arquitectura y su calidad de Arte, mas todos estos escritos insisten en ello, no sólo por el logro de unos privilegios tributarios, o por un prurito de prestigio, como dice F. J. Sánchez Cantón:

"...una idea incrustada en el espíritu de casi todos los artistas cultos del renacimiento, en particular en el de los españoles: la nobleza de la profesión artística..." ${ }^{42}$.

sino porque era una realidad insoslayable para imponer el nuevo modelo de profesional, que si en este momento no está definido, sí la exigencia de una formación profunda que insisten en reclamar y divulgar, lo que les hace ser novedad.

40 Ibidem, pág. E6.

4) A. Rodriguez G. DE Ceballos, «Las Ordenanzas de Madrid de Ardemans y sus ideas sobre Arquitectura", Revista de ldeas Estéticas, 1971, pág. 94-110

42 F. J. Sanchez Canton, obra citada, pág. 58. 